\title{
Artemisinin analogue SM934 ameliorates the proteinuria and renal fibrosis in rat experimental membranous nephropathy
}

\author{
Tian-tian $\mathrm{LI}^{1}$, Xiao-hui ZHANG ${ }^{2}$, Jing-feng $\mathrm{JNG}^{1}$, Xin $\mathrm{LI}^{1}$, Xiao-qian YANG ${ }^{1}$, Feng-hua ZHU ${ }^{1}$, Wei TANG ${ }^{1, *}$, Jian-ping ZUO ${ }^{1,2, *}$ \\ ${ }^{1}$ State Key Laboratory of Drug Research, Shanghai Institute of Materia Medica, Chinese Academy of Sciences, Shanghai 201203, \\ China; ${ }^{2}$ Laboratory of Immunology and Virology, Shanghai University of Traditional Chinese Medicine, Shanghai 201203, China
}

Aim: SM934 is a novel water-soluble artemisinin derivative with immunoregulatory activities that has been used to treat murine lupus nephritis. In the current study, we investigated the effects of SM934 on rat experimental membranous nephropathy.

Methods: Passive Heymann nephritis (PHN) was induced in SD rats by intraperitoneal injection of anti-Fx1A serum. The rats were orally administered SM934 (12.5 and $25 \mathrm{mg} \cdot \mathrm{kg}^{-1} \cdot \mathrm{d}^{-1}$ ) or prednisolone $\left(5 \mathrm{mg} \cdot \mathrm{kg}^{-1} \cdot \mathrm{d}^{-1}\right)$ for $28 \mathrm{~d}$. Blood and urine sample, and kidney tissue were collected for analyses. Human complement C3a-induced injury of HK-2 cells was used for in vitro experiments.

Results: Treatment of PHN rats with SM934 or prednisolone attenuated the progression of glomerulonephritis and renal fibrosis, as evidenced by the reduced level of proteinuria and circulating antibodies, as well as by the reduced immune complex deposition, reversed podocyte injuries, and attenuated tubulointerstitial fibrosis in the kidneys. Furthermore, the two drugs suppressed TGF$\beta 1$ expression and Smad2/3 phosphorylation, and increased Smad7 expression in the kidneys. The two doses of SM934 produced almost identical therapeutic effects on PHN rats. Pretreatment with SM934 or a C3a receptor antagonist blocked the C3a-induced epithelial-mesenchymal transition in HK-2 cells in vitro.

Conclusion: SM934 ameliorates kidney injury and attenuates the tubulointerstitial fibrosis in PHN rats by down-regulation of the TGF$\beta 1 /$ Smad signaling pathway.

Keywords: SM934; artemisinin; prednisolone; membranous nephropathy; passive Heymann nephritis; proteinuria; podocyte; renal fibrosis; TGFß1; Smad; epithelial-mesenchymal transition

Acta Pharmacologica Sinica (2015) 36: 188-199; doi: 10.1038/aps.2014.134; published online 26 Jan 2015

\section{Introduction}

Membranous nephropathy (MN) is one of the leading causes of nephrotic syndrome in adults, which accounts for $10 \%$ of primary glomerulonephritis worldwide, and 30\% in Western countries ${ }^{[1]}$. MN is characterized by the presence of immunocomplex deposits between the glomerular basement membrane (GBM) and the podocyte ${ }^{[2]}$. These immunocomplex deposits include immunoglobulin, complement components ( $\mathrm{C} 3$ and $\mathrm{C} 5 \mathrm{~b}-9)$, and recently identified autologous antigens $^{[3,4]}$. In MN, podocyte injury caused by MAC C5b-9 leads to heavy proteinuria and hypoalbuminemia ${ }^{[5]}$. Renal fibrosis is the final common pathway of almost all chronic kidney diseases $(\mathrm{CKD})^{[6]}$. In the late stage of $\mathrm{MN}$, renal fibrosis is caused by the accumulation of excess extracellular matrix

\footnotetext{
* To whom correspondence should be addressed.

E-mail jpzuo@mail.shcnc.ac.cn (Jian-ping ZUO); tangwei@mail.shcnc.ac.cn (Wei TANG)

Received 2014-08-08 Accepted 2014-10-27
}

(ECM), which is an important indicator of the disease progression of MN. Up to $40 \%$ of MN patients progress to end-stage renal failure, a destructive disorder that requires dialysis or kidney transplantation ${ }^{[7]}$.

During the pathogenic progression of $\mathrm{MN}$, many cytokines (particularly TGF- $\beta 1$ ), chemokines and complement components accumulate in kidney and cause many types of resident kidney cells and infiltrated cells to turn into myofibroblastlike cells to secret ECM (particularly collagen) ${ }^{[8]}$. Among these cells, the tubular epithelial cell that undergoes epithelialmesenchymal transition (EMT) is the most important origin of myofibroblast ${ }^{[9]}$. Recent studies identified that anaphylatoxin C3a produced by C3 cleavage could effectively induce EMT in human tubular epithelial cells ${ }^{[10,11]}$.

Rat passive Heymann nephritis (PHN) is the most commonly used rodent model of human membranous nephropathy. The pathogenic mechanism and clinical manifestations of rat PHN are similar to $\mathrm{MN}$ in humans ${ }^{[12]}$. $\mathrm{PHN}$ is induced by passive administration of anti-Fx1A serum/antibody, 
which can bind to antigens on the podocyte. Consequently, the deposition of immune complexes cause glomerular filtration barrier deterioration, inflammatory cell infiltration, and ECM accumulation, leading to heavy proteinuria and renal fibrosis ${ }^{[13-15]}$.

To date, the common therapy of $\mathrm{MN}$ is a combination of glucocorticoids and immunosuppressive or cytotoxic agents, accompanied by drugs for the other complications, including edema, hypertension and dyslipidemia. Thus, there is an urgent need for novel, effective and safe therapies for MN treatment. SM934, a $\beta$-aminoarteether maleate, synthesized from $\beta$-hydroxyarteether at Shanghai Institute of Materia Medica, is a novel water-soluble artemisinin derivative. Our previous reports have demonstrated that SM934 modulates autoimmune responses in experimental autoimmune encephalomyelitis (EAE) by enhancing the expansion and functions of regulatory $\mathrm{T}$ cells ${ }^{[16]}$ and ameliorates systemic lupus erythematosus (SLE) by inhibiting Th1 and Th17 cell responses, pathogenic T-cell development and by enhancing macrophage IL-10 production. Ample evidence has demonstrated that SM934 treatment can ameliorate the lupus nephritis ${ }^{[17,18]}$. However, whether SM934 could treat other types of nephropathy remains elusive. In the current study, we investigated the effects of SM934 on the rat experimental membranous nephropathy. Our study showed that SM934 treatment suppresses proteinuria and podocyte injury in the PHN rats and attenuates the tubulointerstitial fibrosis by modulating the TGF- $\beta 1 /$ Smad signaling pathway.

\section{Materials and methods}

\section{Animals experiments and ethics statement}

Male Wistar and Sprague-Dawley rats and male New Zealand white rabbits were obtained from Shanghai Laboratory Animal Center of Chinese Academy of Sciences. All rats were housed under specific pathogen-free conditions, and rabbits were housed in clean-grade animal lab. All of the experiments were performed according to the guidelines of the Association for Assessment and Accreditation of Laboratory Animals Care International. All of the animal procedures were conducted in compliance with the animal care and use protocol (2013-01ZJP-19) approved by the Institutional Animal Care and Use Committee (IACUC) at Shanghai Institute of Materia Medica.

Induction, treatment and sample collection of rat passive Heymann nephritis

The Fx1A antigen was prepared from the renal cortex of male Wistar rats as previously described ${ }^{[19]}$. Then, we immunized the New Zealand white rabbits with Fx1A antigen to prepare the rabbit antiserum. PHN was induced in male SpragueDawley rats weighing 180-200 $\mathrm{g}$ by intraperitoneal injection of the rabbit anti-Fx1A antiserum ( $3 \mathrm{~mL} / 200 \mathrm{~g}$ body weight).

The rats were randomly divided according to proteinuria level at $\mathrm{d} 4$ after PHN induction; oral treatment started on d 5 and continued until d 32. PHN rats were divided into 4 groups ( $n=12$ per group): vehicle group (saline), prednisolone control group (PNS, $5 \mathrm{mg} \cdot \mathrm{kg}^{-1} \cdot \mathrm{d}^{-1}$ ), and SM934 treated groups
(25 and $12.5 \mathrm{mg} \cdot \mathrm{kg}^{-1} \cdot \mathrm{d}^{-1}$ ). Eight of the healthy SD rats were chosen as normal controls.

On d 4, 7, 13, 18, and $32 \mathrm{~d}$ post PHN induction, blood and urine samples were collected. The blood samples were taken from the retrobulbar plexus of the pentobarbital sodiumanesthetized rats. The $24-\mathrm{h}$ urine collections were done on individual rats in metabolic cages. At the endpoint of the animal experiment, $32 \mathrm{~d}$ after PHN induction, all of the rats were sacrificed and kidneys were collected.

\section{Biochemical parameters, circulating rat anti-rabbit antibody, and hydroxyproline detection}

The protein content in the urine was measured by the Bradford method. The serum albumin (ALB) level was determined by the HITACHI-7080 automatic biochemical analyzer (Hitachi, Tokyo, Japan).

The titer of circulating rat anti-rabbit antibody was determined by ELISA. Briefly, era 96-well plates were coated with $4 \mu \mathrm{g} / \mathrm{mL}$ rabbit IgG (Sigma-Aldrich Co LLC, St Louis, MO, USA) in sodium carbonate buffer ( $\mathrm{pH}$ 9.6) and incubated overnight at $4^{\circ} \mathrm{C}$. After blocking and washing, the rat serum samples, which were diluted, were added and incubated for $2 \mathrm{~h}$ at room temperature. After washing, the HRP labeled sheep polyclonal antibody against rat (1:10000, Abcam, Cambridge, UK) was applied and incubated for $1 \mathrm{~h}$. Then, we added the substrate and detected absorbance at 450 and $570 \mathrm{~nm}$ with an ELISA-reader (Thermo scientific, Waltham, MA, USA).

Hydroxyproline (Hyp) was quantified colorimetrically. The samples of $50 \mathrm{mg}$ wet weight kidney tissue were homogenized and incubated with $12 \mathrm{~mol} / \mathrm{L} \mathrm{HCl}$ at $120^{\circ} \mathrm{C}$ for $3 \mathrm{~h}$. Then, a Hydroxyproline Assay Kit (Sigma-Aldrich CO LLC, St Louis, MO, USA) was used to detect the Hyp concentration.

\section{Renal histopathological and immunofluorescent examination}

Formalin-fixed kidney tissues were dehydrated in graded alcohol, embedded in paraffin, and stained with hematoxylin and eosin. Briefly, the histological pathology was scored as follows: 0 , normal; 1 , minimal; 2 , mild; 3, moderate; 4, marked; 5, severe ${ }^{[20]}$.

The snap-frozen kidney tissues were used for immunofluorescence examination of IgG, C3, C5b-9, podocin and desmin. The frozen renal tissue was embedded in Tissue-Tek OCT compound and cut in a cryostat (Leica, Solms, Germany). The 6- $\mu \mathrm{m}$ cryosections were fixed in acetone, after blocking and washing, stained with fluorescein isothiocyanate (FITC)conjugated goat anti-rat IgG (1:200, Millipore, Merck KGaA, Damstadt, Germany), rabbit anti-rat C3 (1:200, Novus Biologicals, LLC, Littleton), mouse anti-rat C5b-9 (1:100, Abcam, Cambridge, UK), rabbit anti-podocin (1:200, Sigma-Aldrich CO LLC, St Louis, MO, USA), and rabbit anti-desmin (1:100, Abcam, Cambridge, UK), which were followed by FITC-conjugated goat anti-rabbit IgG (1:200, Abcam, Cambridge, UK) and FITC-conjugated goat anti-mouse IgG (1:200, Beyotime, Haimen, Jiangsu, China). The sections were examined by immunofluorescence microscope (Nikon, Tokyo, Japan), all exposure settings were kept constant for each section. The 
fluorescence intensity was measured by Histogram Command in Adobe Photoshop.

For the transmission electron microscopy (TEM) assay, blocks of renal cortex tissue $\left(1 \mathrm{~mm}^{3}\right)$ were fixed in cold $3.75 \%$ glutaraldehyde for 5 months. After washing in $0.1 \mathrm{~mol} / \mathrm{L}$ phosphate buffer ( $\mathrm{pH} 7.5$ ) for 5 times, renal tissues were post fixed in $2 \%$ osmium tetroxide for $1.5 \mathrm{~h}$, dehydrated in graded acetone and ethanol, and embedded in epoxy resin. The ultrathin sections (80-90 nm) were stained with uranyl acetate and lead citrate, then examined and photographed in a Hitachi 7500 transmission electron microscope (Hitachi, Tokyo, Japan).

\section{HK-2 cells culture}

The immortalized proximal tubule epithelial cell line from normal adult human kidney, HK-2 cells (CRL-2190, American Type Culture Collection, Manassas, VA, USA), were a type gift from the Center for Drug Safety Evaluation and Research, SIMM, CAS. The HK-2 cells were cultured in DMEM/F12 medium (Gibco, Grand Island, NY, USA) containing 10\% fetal bovine serum at $37^{\circ} \mathrm{C}$ and were starved from FBS for $24 \mathrm{~h}$ before all of the experiments. The HK-2 cells were induced by recombinant human C3a (50 nmol/L; Calbiochem, Merck KGaA, Darmstadt, Germany) for $24 \mathrm{~h}$. Before C3a application the HK-2 cells were pretreated with C3aRA (C3a receptor antagonist, 1 mol/L, SB-290157, Calbiochem, Merck KGaA, Darmstadt, Germany) and SM934 (500 $\mathrm{mmol} / \mathrm{L})$ for $24 \mathrm{~h}$.

$\alpha$-smooth muscle actin ( $\alpha$-SMA) and E-cadherin immunofluorescence staining

For immunofluorescence staining, HK-2 cells were cultured on non-coated, glass coverslips. After C3a and drug treatment, cells were rinsed with PBS twice, fixed with $4 \%$ paraformaldehyde in PBS for $10 \mathrm{~min}$ at room temperature, and blocked with $10 \%$ BSA in PBS for $1 \mathrm{~h}$. The primary antibodies that recognize a-SMA and E-cadherin (mouse anti-a-SMA, 1:200, Sigma-Aldrich Co LLC, St Louis, MO, USA, and rabbit antiE-cadherin, 1:200, Cell Signaling Technology, Danvers, MA, USA) and the secondary antibody that was conjugated with FITC (Abcam, Cambridge, UK) were diluted in blocking buffer containing $0.1 \%$ saponin. The nuclei were counterstained with $5 \mu \mathrm{g} / \mathrm{mL}$ DAPI. The specimens were viewed using a fluorescence microscope with a $\times 60$ objective (Olympus, Tokyo, Japan).

\section{Western blot analysis}

The kidney tissues were homogenized. The glomeruli of experimental rats were isolated using a graded sieving method $^{[21]}$. The homogenates, glomeruli or HK-2 cells were rinsed with PBS containing proteinase inhibitor (Roche, Mannheim, Germany), and lysed with lysis buffer (Thermo Scientific, Waltham, MA, USA). Then, the lysates were boiled for $5 \mathrm{~min}$ at $100^{\circ} \mathrm{C}$ in SDS sample buffer $(62.5 \mathrm{mmol} / \mathrm{L}$ Tris$\mathrm{HCl}, \mathrm{pH}$ 6.28; 2\% SDS; $10 \%$ glycerol; 5\% 2-mercaptoethanol; and $0.02 \%$ bromophenol blue). The samples were submitted to $8 \%$ sodium dodecyl sulfate-polyacrylamide gel electrophoresis (SDS-PAGE) and transferred onto NC membrane. The following primary antibodies were added in optical dilution: anti-nephrin (Abcam, Cambridge, UK), anti-podocin, anti-desmin, anti-a-SMA, anti-ED-1 (Santa Cruz Biotechnology, Dallas, Texas, USA), anti-TGF- $\beta 1$, anti-Smad2/3, anti-p-Smad2/3 (the three antibodies were all from Cell Signaling Technology, Danvers, MA, USA), anti-Smad7 (Santa Cruz Biotechnology, Dallas, Texas, USA), and anti- $\beta$-actin (Abcam, Cambridge, UK). Primary antibodies for HK-2 cell sample were as follows: anti-a-SMA, anti-E-cadherin, and anti-GAPDH (Abcam, Cambridge, UK). Subsequently, the bound secondary antibodies were detected with a chemiluminescence detection system (GE, Connecticut, USA) and exposed to X-ray film (Sigma-Aldrich Co LLC, St Louis, MO, USA). The results were quantified using QuantityOne (Bio-Rad Laboratories, Munich, Germany).

\section{Real-time PCR}

The total RNA was isolated from HK-2 cells using Trizol reagent (Invitrogen, Carlsbad, CA, USA), and a one-step real-time PCR assay was performed with SYBR Green PCR Reagents (Qiagen, Valencia, CA, USA) and a Continuous Fluorescence Detection System (MJ Research, USA). Relative quantitation of mRNA expression of collagen I and GAPDH was calculated using the $\triangle \Delta \mathrm{Ct}$ method. The forward and reverse primers for collagen I and GAPDH were as follows: GAPDH forward 5'-TGG AAA TCC CAT CAC CAT CT-3', GAPDH reverse: 5'-TGG ACT CCA CGA CGT ACT CA-3'; collagen I forward 5'-GCC TCA AGG TAT TGC TGG AC-3'; collagen I reverse 5'-ACC TTG TTT GCC AGG TTC AC-3'.

\section{Statistical analysis}

Student's t-test and one-way analysis of variance (ANOVA) with Newman-Keuls multiple comparisons on post-tests were used to compare differences between groups. Histological scores were analyzed using Kruskal-Wallis test followed by the Mann-Whitney U test without correction of multiple comparisons. $P<0.05$ was considered statistically significant.

\section{Results}

Effects of SM934 on proteinuria, serum albumin and circulating rat anti-rabbit IgG antibodies in PHN rats

Significant proteinuria, approximately 45-50 mg/d, occurred $4 \mathrm{~d}$ after the PHN induction. The peak was more than 600 $\mathrm{mg} / \mathrm{d}$, and the value of proteinuria was still above $200 \mathrm{mg} / \mathrm{d}$ at $\mathrm{d}$ 32. Oral administrations of SM934, PNS and vehicle were started on $\mathrm{d} 5$ and lasted until the end of the experiment (d 32). As shown in Figure 1A, the oral administration of SM934 for $28 \mathrm{~d}$, at the doses of both 25 and $12.5 \mathrm{mg} / \mathrm{kg}$, significantly reduced proteinuria. Compared to the PNS positive control group, which began to reduce the proteinuria dramatically after $14 \mathrm{~d}$ of treatment, SM934 treatment suppressed proteinuria, even at the beginning of the treatment.

Hypoalbuminemia also occurred in PHN rats; the serum albumin level declined sharply during the first $7 \mathrm{~d}$ after PHN induction and then gradually returned to previous levels. In this study, the average level of ALB in normal rats 

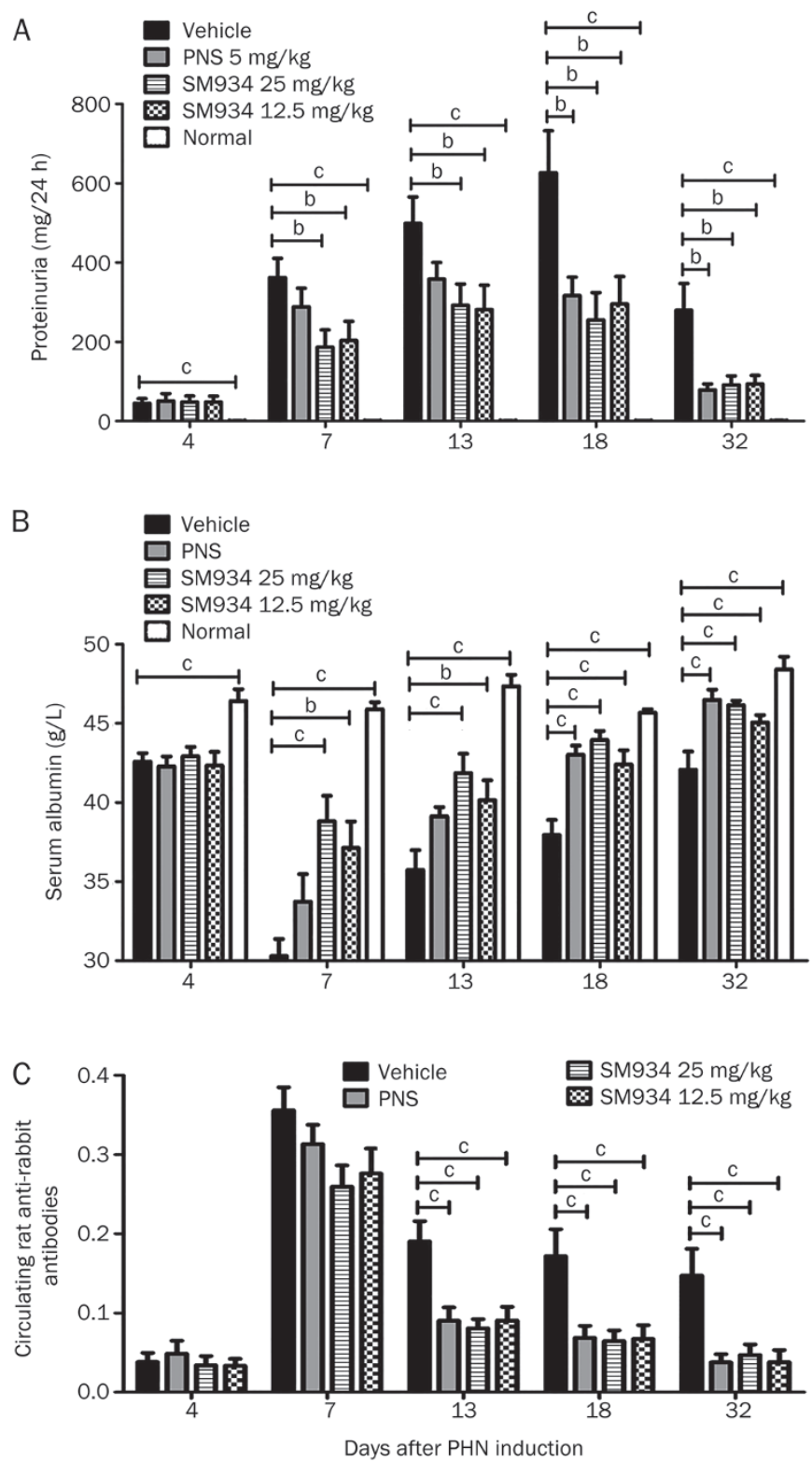

Figure 1. Effect of SM934 on proteinuria (A), serum albumin (B) and circulating rat anti-rabbit IgG antibodies $(\mathrm{C})$ in $\mathrm{PHN}$ rats. The SD rats were induced with PHN by injection of rabbit anti-Fx1A antiserum and were treated with a vehicle (saline), PNS (5 mg/kg), and SM934 $(25,12.5$ $\mathrm{mg} / \mathrm{kg}$ ) for $28 \mathrm{~d}$ ( $n=12$ per group). ${ }^{\mathrm{b}} P<0.05,{ }^{\mathrm{c}} P<0.01 \mathrm{vs}$ vehicle treatment group.

was approximately $46.6 \mathrm{~g} / \mathrm{L}$, and the ALB of vehicle group decreased to $30.29 \mathrm{~g} / \mathrm{L}$ at d 7 after PHN induction. SM934 treatment restored the ALB very well through the whole process. At d 32, in both the SM934 and PNS treatment groups, ALB levels returned to nearly normal (Figure 1B).

Because the rabbit antiserum was injected into rats, the rat's immune system could recognize these heterologous antigens and produced high level of rat anti-rabbit antibodies. In our experiment, the $O D$ value of circulating anti-rabbit IgG in nor- mal rats was $0.008 \pm 0.003$, and it increased to $0.356 \pm 0.087$ in the vehicle group $7 \mathrm{~d}$ after PHN induction, then decreased slowly. As shown in Figure 1C, SM934 treatment at the doses of both 25 and $12.5 \mathrm{mg} / \mathrm{kg}$ showed a strong potential for reducing the circulating rat anti-rabbit antibodies.

\section{Effects of SM934 on renal morphology and histopathology}

Due to the continuous extracellular matrix accumulation, renal fibrosis was serious in the late stage of PHN. At the end of the experiment, the induction of PHN resulted in a $28.5 \%$ increase in kidney weight/body weight ratio $(\mathrm{KW} / \mathrm{BW})^{[22,23]}$ in comparison with the untreated normal control rats $(P<0.001)$. On the contrary, the $(\mathrm{KW} / \mathrm{BW})$ of the SM934 treatment groups were almost the same with that of normal control (Figure 2A).

Light-microscopy examination showed that vehicle-treated PHN rats exhibited severe renal damage, characterized by protein casts in tubules, tubular dilation and atrophy, and interstitial inflammatory cells infiltration (Figure 2B). Marked alleviation of renal damage was observed in SM934 treated groups. The results showed that SM934 treatment markedly ameliorated the tubular damage and reduced the interstitial inflammatory cells infiltration (representative pictures and the histopathological scores were in Figure 2B and 2C).

\section{Effects of SM934 on IgG, C3, C5b-9 deposition in PHN rat kidneys}

According to the pathogenesis of rat PHN, the antibodies in rabbit antiserum occur in the kidney and recognize megalin, which exists on podocyte and tubular epithelia ${ }^{[13,14]}$, then the rat autologous antibodies recognize rabbit IgG and deposit to form an immune complex. The PHN rat displayed pronounced autologous IgG deposition in glomeruli, dispersing along the capillary wall (representative immunofluorescence pictures in Figure 3A). The fluorescence intensity analysis revealed that rat IgG deposition was diminished remarkably by SM934 treatment (Figure 3D, $25 \mathrm{mg} / \mathrm{kg}$ group, $P<0.01 ; 12.5$ $\mathrm{mg} / \mathrm{kg}$ group, $P<0.05)$.

The complement system plays an important role in disease progression, such as deteriorating the glomerular filtration barrier and inducing renal fibrosis. In human $\mathrm{MN}, \mathrm{C} 3$, and C5b-9 depositions in the kidney are typical, and they are also found in PHN animal kidneys ${ }^{[12,24,25]}$. As shown in Figure 3B and $\mathrm{C}$, at the end point of the experiment, pronounced and scattered C3 and C5b-9 deposited in both glomeruli and renal tubules in the PHN rat. In contrast, SM934 treatment significantly decreased C3 and C5b-9 deposition (Figure 3E, 3F, $P<0.001)$.

\section{Effects of SM934 on expression of podocin, nephrin and desmin} in PHN rat kidneys

The visceral glomerular epithelial cell, podocyte, is the major component of glomerular filtration barrier, and its dysfunction can induce proteinuria directly ${ }^{[26]}$. In membranous nephropathy, podocyte damage is characterized by slit diaphragm alteration and foot process effacement deterioration, or even 
A
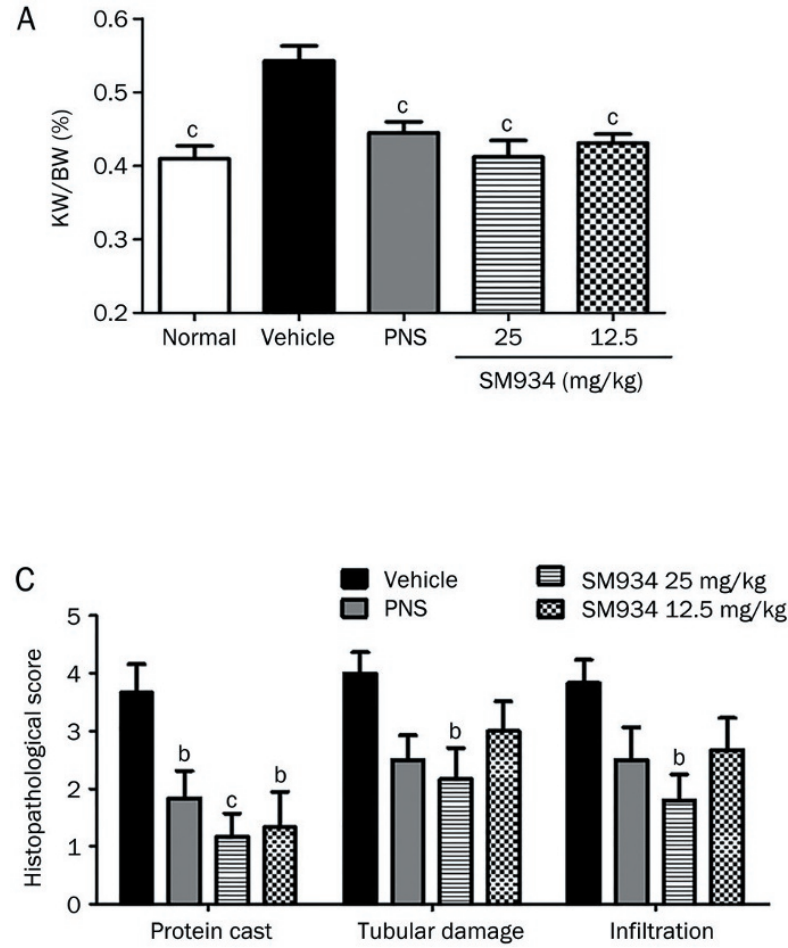

B
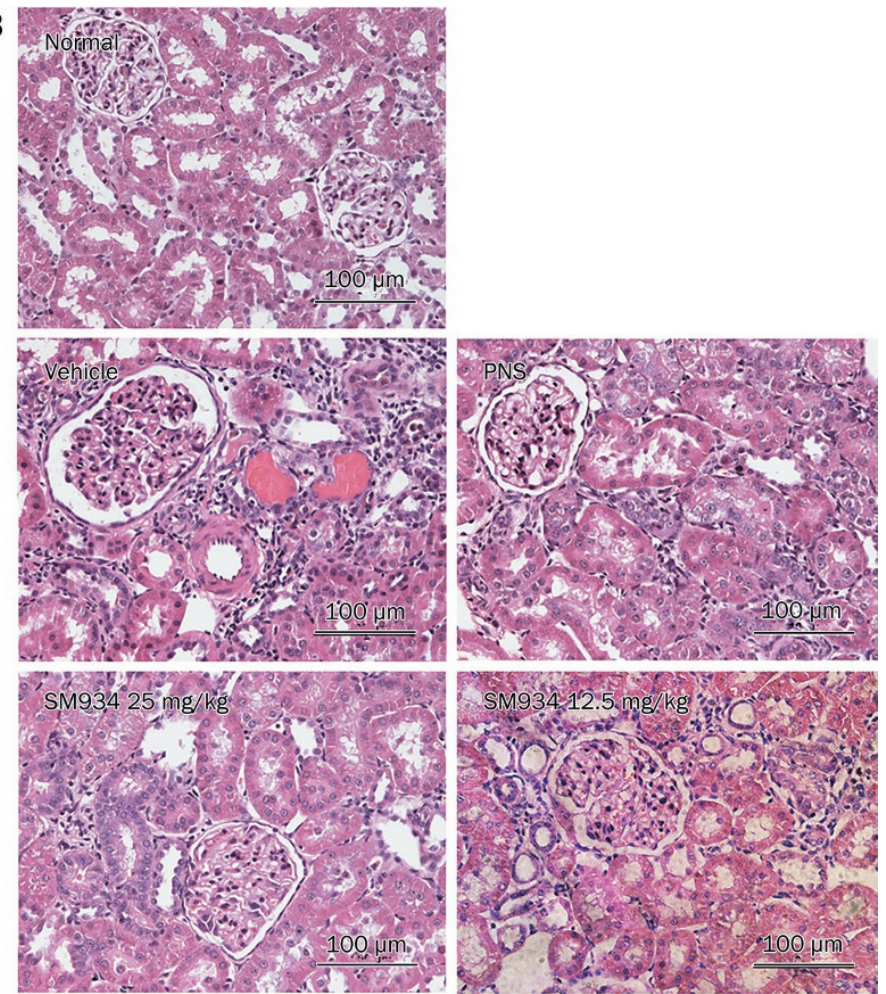

Figure 2. Effects of SM934 on renal morphology and histopathology in the PHN rat kidneys. (A) Changes of kidney weight/body weight ratio (KW/BW) in PHN rat. (B) Representative kidney sections stained with H\&E (original magnification $\times 200$ ). (C) The histopathological scores of each group on tubular protein cast, tubular damage (tubular dilation and atrophy), tubulointestinal inflammatory cell infiltration. ${ }^{\mathrm{b}} P<0.05,{ }^{\mathrm{C}} P<0.01$ vs vehicle treatment group.

apoptosis. The results of the TEM observations indicated that podocyte injuries in PHN could be reversed after treatment with SM934 (Figure 4A).

Podocin and nephrin are important proteins expressed, respectively on the slit diaphragm and the cell body of podocytes, and they play central role in keeping the normal morphology and function of podocyte ${ }^{[27]}$. At the end point of our experiment ( $32 \mathrm{~d}$ after induction of PHN), the reduced expression of podocin and nephrin were observed in the PHN rats. As shown in Figure 4B, podocin dispersed as a linear pattern along glomerular capillary wall in normal control rats; but the distribution turned to dot-like and the structure of glomerular became relaxed in the PHN rats. The results showed SM934 treatment could maintain the expression and distribution of podocin (Figure 4B, 4D, 4F, 4G). The Western blot results also revealed SM934 treatment at the dose of $25 \mathrm{mg} / \mathrm{kg}$ improved nephrin expression in glomeruli remarkably (Figure 4F, 4G, $P<0.05)$.

The abnormally high expression of desmin in glomeruli is a biomarker of podocyte injuries ${ }^{[28]}$. In our experiment, the anti-desmin antibody reacted weakly in the normal rat kidneys, while enhanced staining of desmin was obvious in the model rats (Figure 4C), which suggested the podocytes were damaged in the PHN model. The quantification results of the fluorescence intensity and the Western blot analysis showed that SM934 treatment efficiently protected the podocyte from injuries in PHN rats (Figure 4E, 4G).

\section{Effects of SM934 on renal fibrosis in the PHN rats}

Fibrosis is the primary manifestation at the end stage of MN. ECM deposition is the hallmark of renal fibrosis. Masson's trichrome staining showed that at the end point of the experiment, the PHN rat kidneys were filled with masses of ECM, compared to the vehicle group, and the SM934 treatment groups were in much better condition (Figure 5A). Collagen is the major component of ECM, and Hyp is an amino acid unique to all collagens, and it represents mainly in the type I and III collagens. The amounts of Hyp in kidneys were determined. Compared with the normal control group (55.27 \pm 11.01 $\mu \mathrm{g} / \mathrm{g}$ ), the value of the vehicle treatment group was almost twice that of the normal control group $(119.8 \pm 22.97 \mu \mathrm{g} / \mathrm{g})$. The SM934 treatment at the doses of 25 and $12.5 \mathrm{mg} / \mathrm{kg}$ effectively reduced the amounts of Hyp to $74.51 \pm 16.03$ and $93.6 \pm 11.53$ $\mu \mathrm{g} / \mathrm{g}$, respectively $(P<0.001, P<0.01$, Figure $5 \mathrm{~B})$.

In addition, the expression of a-SMA, the hallmark of interstitial myofibroblasts, was examined. Western blot results showed that a-SMA was markedly increased in the PHN rats and that the SM934 treatments significantly reduced the a-SMA expression in cortical interstitia of the PHN rats $(P<0.001$, Figure 5B).

Furthermore, the infiltration of ED-1-positive monocyte/ macrophage was detected. As shown in Figure 5B, the PHN induction caused a massive infiltration of ED-1-positive monocyte/macrophage, and the SM934 $(25 \mathrm{mg} / \mathrm{kg})$ treatment effectively decreased the infiltration. 

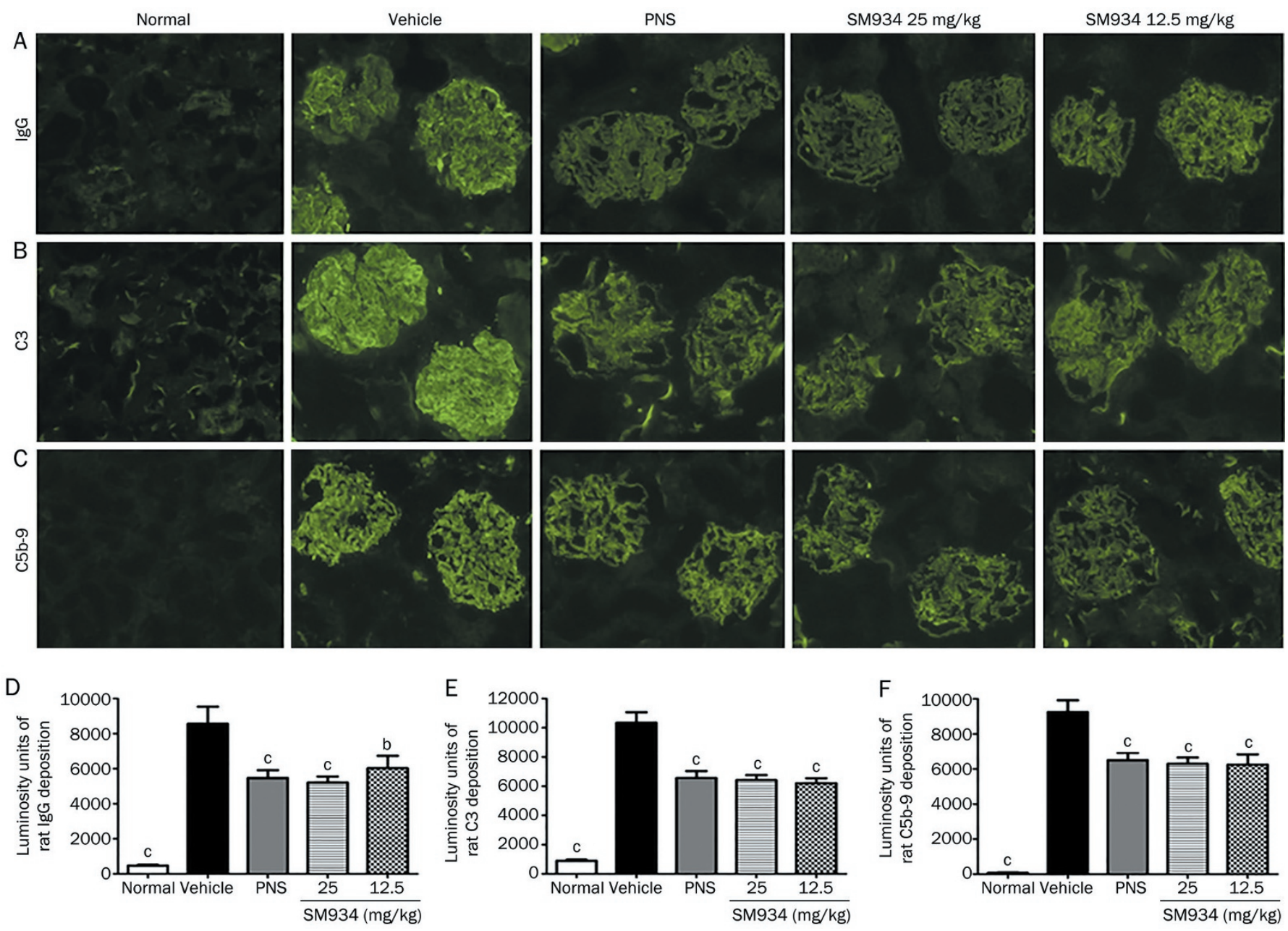

Figure 3. Effects of SM934 on immune complexes deposition in PHN rat kidney (magnification, $\times 200)$. The immunofluorescence staining and quantitation of fluorescence intensity both showed SM934 treatment for 28 d decreased the rat autologous IgG (A, D), C3 (B, E), and C5b-9 (C, F) deposition. ${ }^{\mathrm{b}} \mathrm{P}<0.05,{ }^{\mathrm{c} P}<0.01$ vs vehicle treatment group.

\section{Effects of SM934 on TGF- $\beta 1 /$ Smad signaling pathway}

The TGF- $\beta 1 /$ Smad signaling pathway is one of the most important pro-fibrosis pathways in renal fibrosis. Smad2 and Smad3 proteins have been identified to be phosphorylated by activated TGF- $\beta$ receptors, and the inhibitory Smad protein, Smad7, is degraded under the disease condition ${ }^{[6]}$. To dissect the underlying mechanism of the anti-fibrosis property of SM934, we examined the expression of TGF- $\beta 1$ and its downstream Smad signaling pathway.

In the normal rats' kidneys, only trace levels of TGF- $\beta 1$ were detected. However, a massive increase of TGF- $\beta 1$ was detected in the vehicle group at $32 \mathrm{~d}$ after induction of PHN. On the contrary, the SM934 treatments ( 25 and $12.5 \mathrm{mg} / \mathrm{kg}$ ) decreased the PHN-induced expression of TGF- $\beta 1$ significantly $(P<0.001, P<0.05)$ (Figure 6A, 6B)

The Western blot analysis showed that $\mathrm{p}-\mathrm{Smad} 2$ and p-Smad3 but total Smad2 or Smad3 were markedly reduced (Figure 6A) with the SM934 treatment at doses of both 25 and $12.5 \mathrm{mg} / \mathrm{kg}$ in the PHN rats on d 32 (Figure 6C, p/T Smad2,
$P<0.001$ and $P<0.05$; Figure $6 \mathrm{D}, \mathrm{p} / \mathrm{T} \operatorname{Smad} 3, P<0.01$ and $P<0.05)$. In contrast, the expression of Smad7 was increased significantly in the SM934 treatment group (Figure 6E, $P<0.001)$.

\section{Effects of SM934 on the EMT induced by C3a in HK-2 cells}

The complement system is activated in the PHN rats. Massive levels of anaphylatoxin C3a is released by C3 cleavage during the process. C3a can act on tubular epithelial cells through the C3a receptor $(\mathrm{C} 3 \mathrm{aR})$ to induce EMT and finally result in renal fibrosis $^{[10]}$. To decipher the effect of SM934 on EMT induced by C3a, we chose to study the HK-2 cell line, a normal human proximal tubular epithelial cell line.

Under normal conditions, HK-2 cells display cobblestone morphology of epithelial cells and express E-cadherin on the cell surface. The C3a stimulation induced profound phenotypic changes, particularly elongation in shape, the expression of a-SMA and collagen I, and the reduction of E-cadherin (Figure 7). The results of the Western blot analysis as well as 

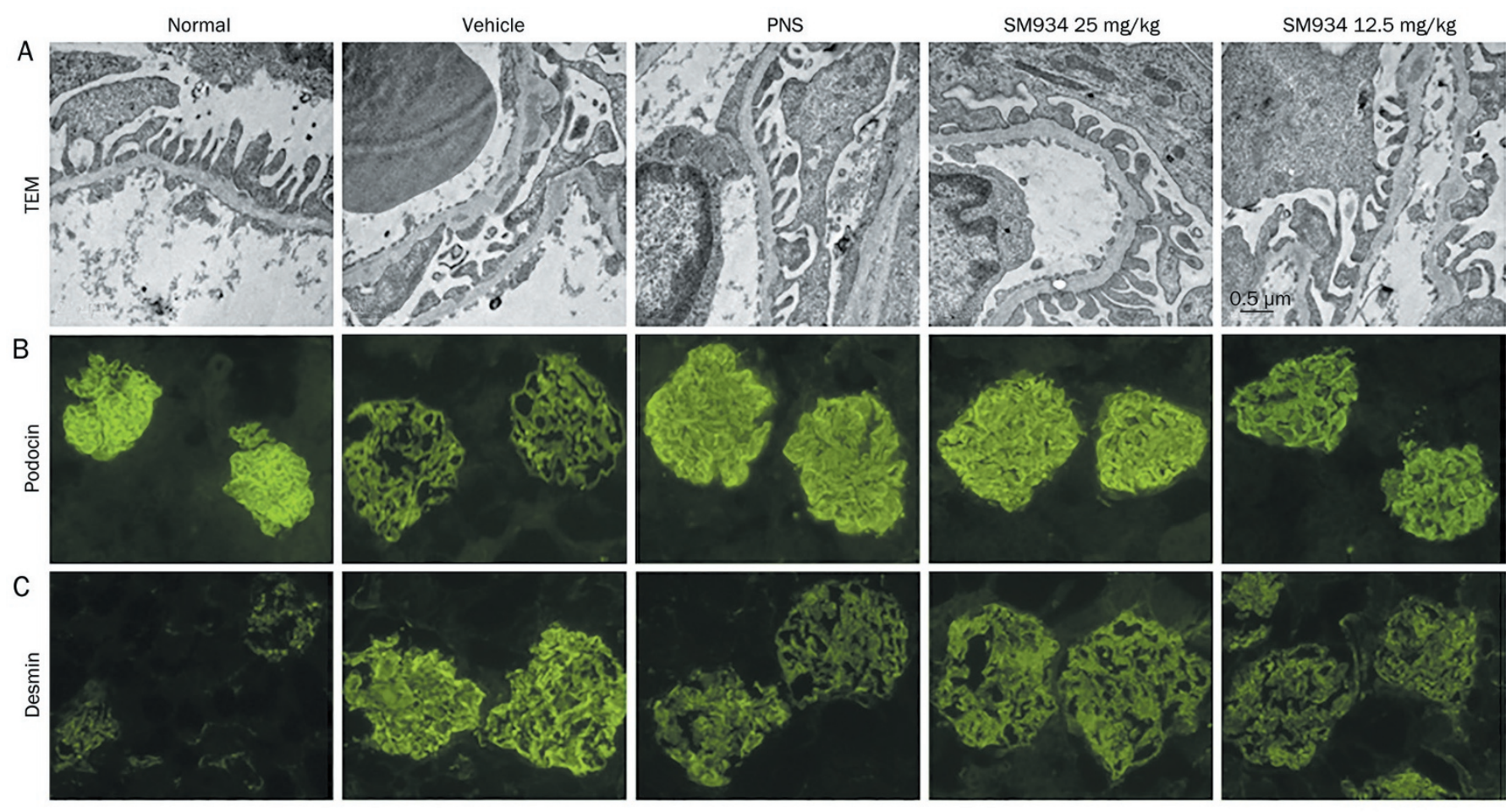

D

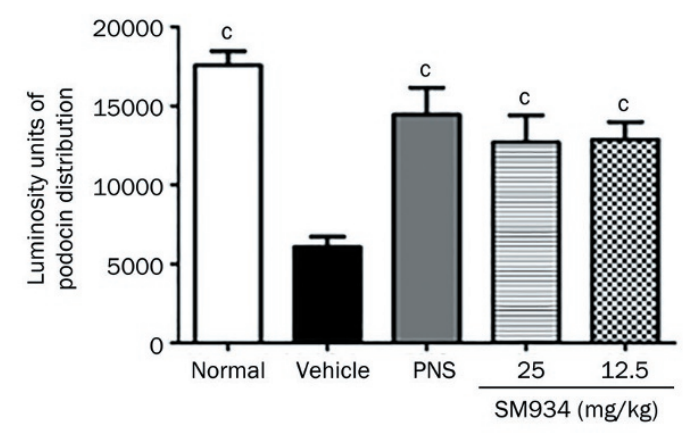

F

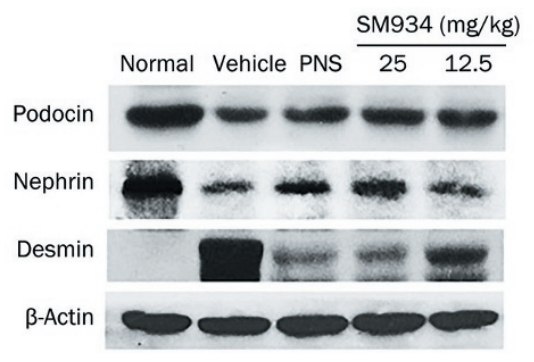

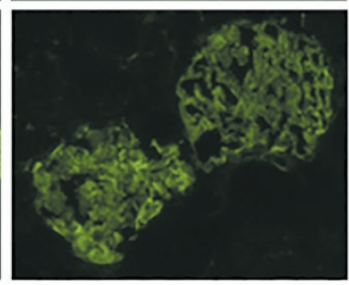
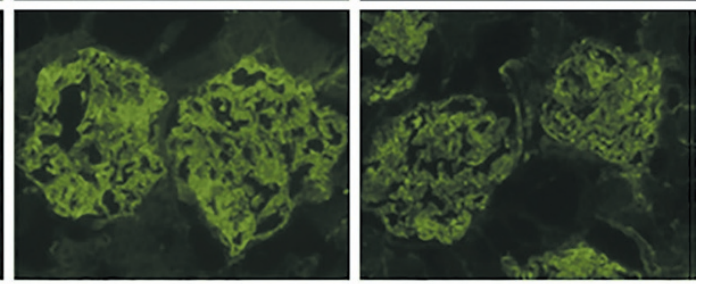

E

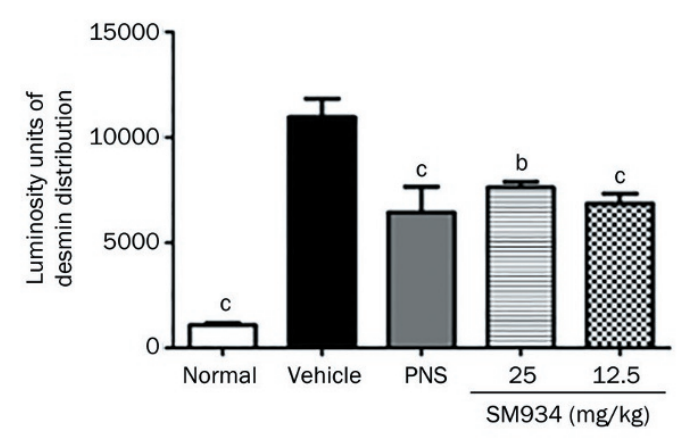

G

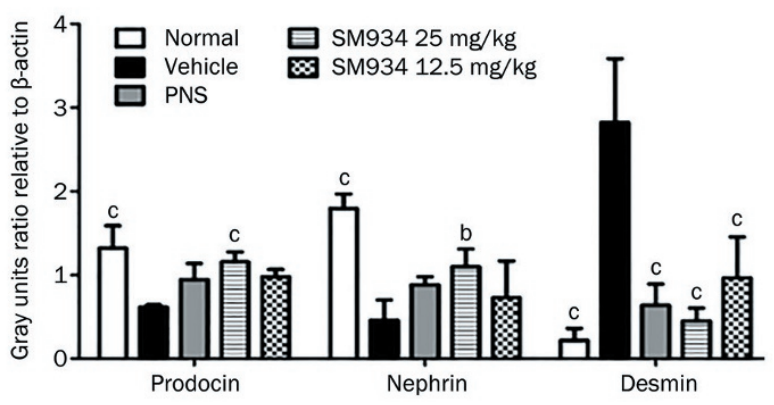

Figure 4. SM934 treatment protected the podocyte in PHN rat kidneys. The transmission electron microscopy (TEM; original magnification $\times 10000$ ) results (A) shows that the foot process effacement in PHN rat was improved and reversed after treatment with SM934. The immunofluorescence staining and quantification of the luminosity of podocin $(B, D)$ and desmin $(C, E)$ in each group (original magnification $\times 200$ ). $(F, G)$ The Western blot results of podocin, nephrin and desmin expression in glomeruli. ${ }^{b} P<0.05,{ }^{C} P<0.01$ vs vehicle treatment group.

confocal and real-time PCR assay showed that EMT induced by C3a in HK-2 cells was largely diminished by SM934 (Figure 7A-7C), without obvious observed cytotoxicity. Taken together, these data clearly indicated that SM934 effectively attenuated the transformation from tubular epithelial cells into myofibroblasts and reduced ECM production in the HK-2 cells. 

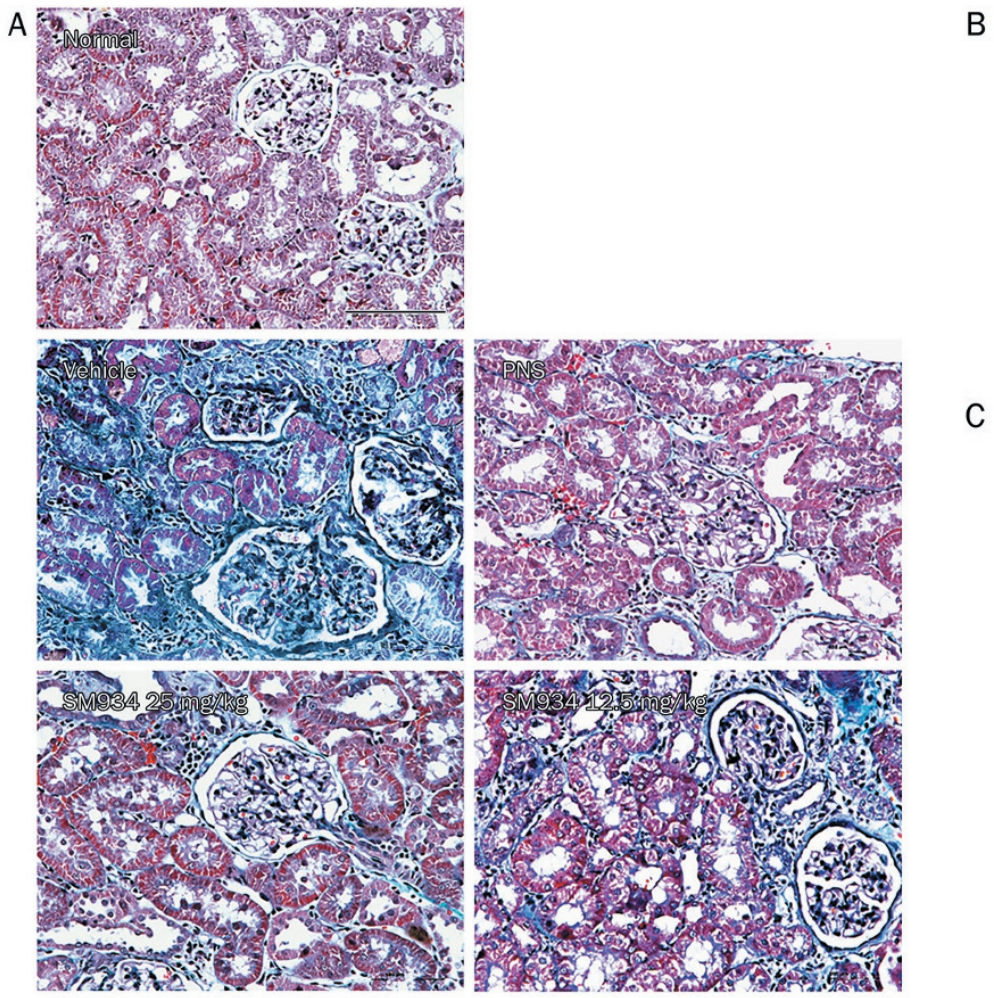

\section{B}
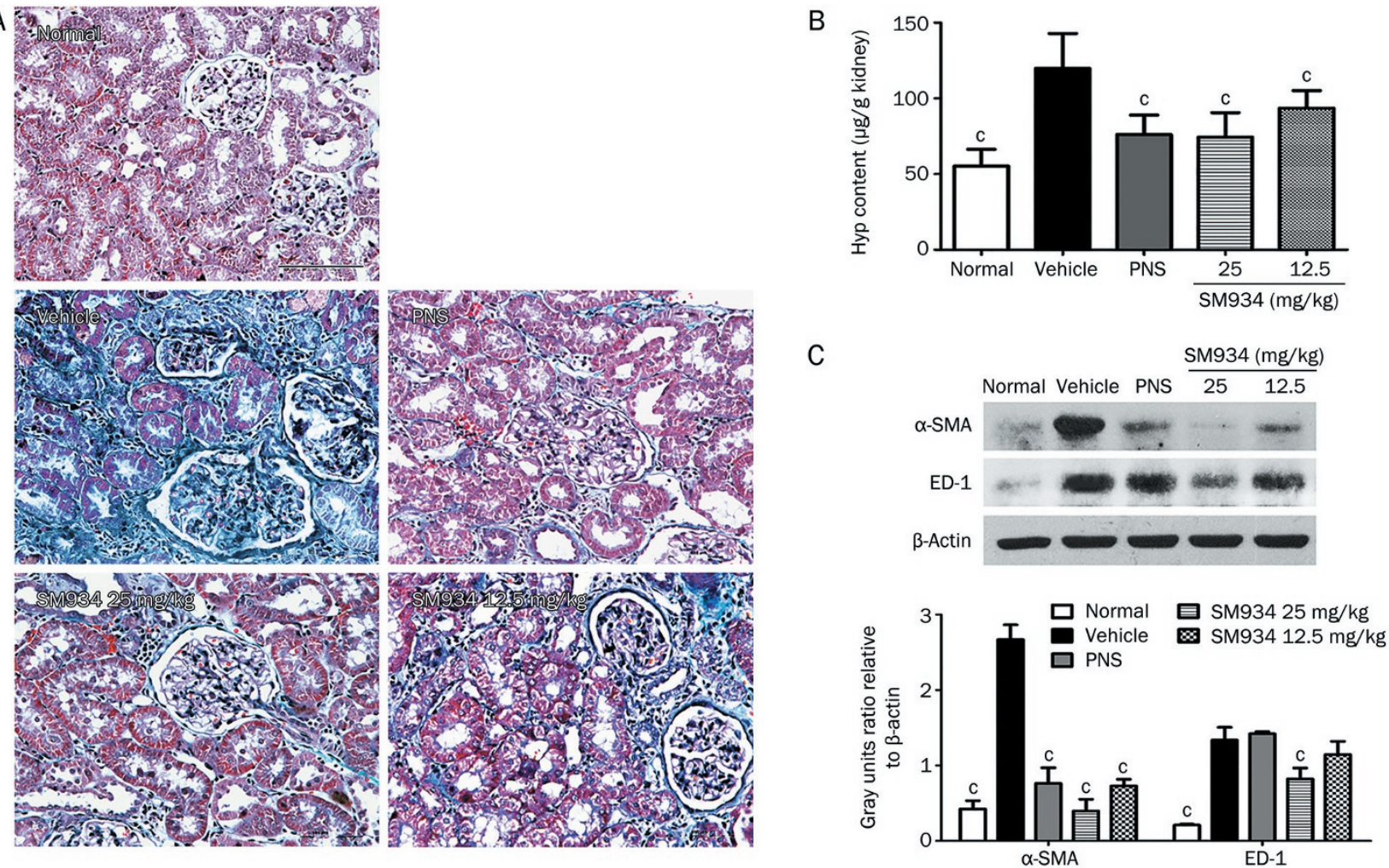

Figure 5. SM934 attenuated the renal fibrosis in PHN rat. (A) Representative kidney sections stained with Masson's trichrome (original magnification $\times 200$ ). (B) The Hyp content in kidney tissue of each group. (C) Western blot results of $\alpha$-SMA and ED-1 expression in kidney at d 32 after PHN induction. ${ }^{\mathrm{C}} P<0.01$ vs vehicle treatment group.

\section{Discussion}

SM934, a novel water-soluble artemisinin derivative, has been reported to possess immunoregulatory properties ${ }^{[2,30]}$. Our previous studies demonstrated that SM934 treatment could significantly decrease the proteinuria, reverse the autoantibody levels, reduce the immune complex deposition in the kidneys, and ameliorate the lethal renal injury in lupus-prone $\mathrm{NZB} / \mathrm{W} \mathrm{F}_{1}$ and MRL/lpr mice ${ }^{[17,18]}$. In the current study, we further demonstrated that SM934 treatment ameliorated the progression of proteinuria and renal fibrosis in rats with PHN by protecting the podocyte, reducing the immune complexes deposition, weakening the TGF- $\beta 1 /$ Smad signaling pathway, and blocking TEMT process.

Rat PHN is a classical animal model of human idiopathic MN. The disease process of PHN is divided into a heterologous phase and an autologous phase ${ }^{[12]}$. During the heterologous phase, the injected heteroantibodies recognize and bind to the antigens in glomeruli, which cause a transient proteinuria. In the following days, the recipient rats can develop an immune response to the heterologous antibodies, the autologous antibodies bind to the heterologous antibody in the glomerulus, which incites a new phase of nephritis. In our experiment, proteinuria was observed $4 \mathrm{~d}$ after antiserum injection, and we started treatment with SM934 at that time to ensure the treatment continued throughout the whole autologous phase.
After treatment with SM934, the proteinuria was markedly inhibited, and the serum ALB level was raised in the rat PHN model. The antiproteinuric effect was associated with a decrease in the podocyte injury marker desmin, and the restoration of the podocyte's innate protein podocin and nephrin expression. These results suggest that SM934 has the potential of reducing proteinuria and protecting the podocyte during kidney injury.

It has been reported that $\mathrm{C} 3$ deposition became clearly positive on $\mathrm{d} 2$ and significant podocyte injury could be detected on $\mathrm{d} 7$ in PHN rats ${ }^{[31,32]}$. In the current study, the results showed that the titer of the circulating rat anti-rabbit IgG antibodies and the deposition of IgG, C3, C5b-9 in PHN rats were significantly decreased after the treatment with SM934. The effects of SM934 demonstrated its antiproteinuric function and its ability to modulate the pathogenesis of PHN.

Proteinuric states tend to initiate the intrarenal inflammatory response and accelerate the renal fibrogenesis ${ }^{[33-35]}$. In the late stage of both human $\mathrm{MN}$ and rat PHN, inflammatory cell infiltration and renal fibrosis are very common. The histopathological sections demonstrated that SM934 markedly attenuates both interstitial inflammatory cell infiltration (especially the ED-1 positive macrophage) and tubular damage in PHN rat. Fibrogenesis is characterized by the accumulation of excessive ECM; collagen is the major component of ECM, and the myofibroblast is the principle source of ECM. SM934 reduced the 
A
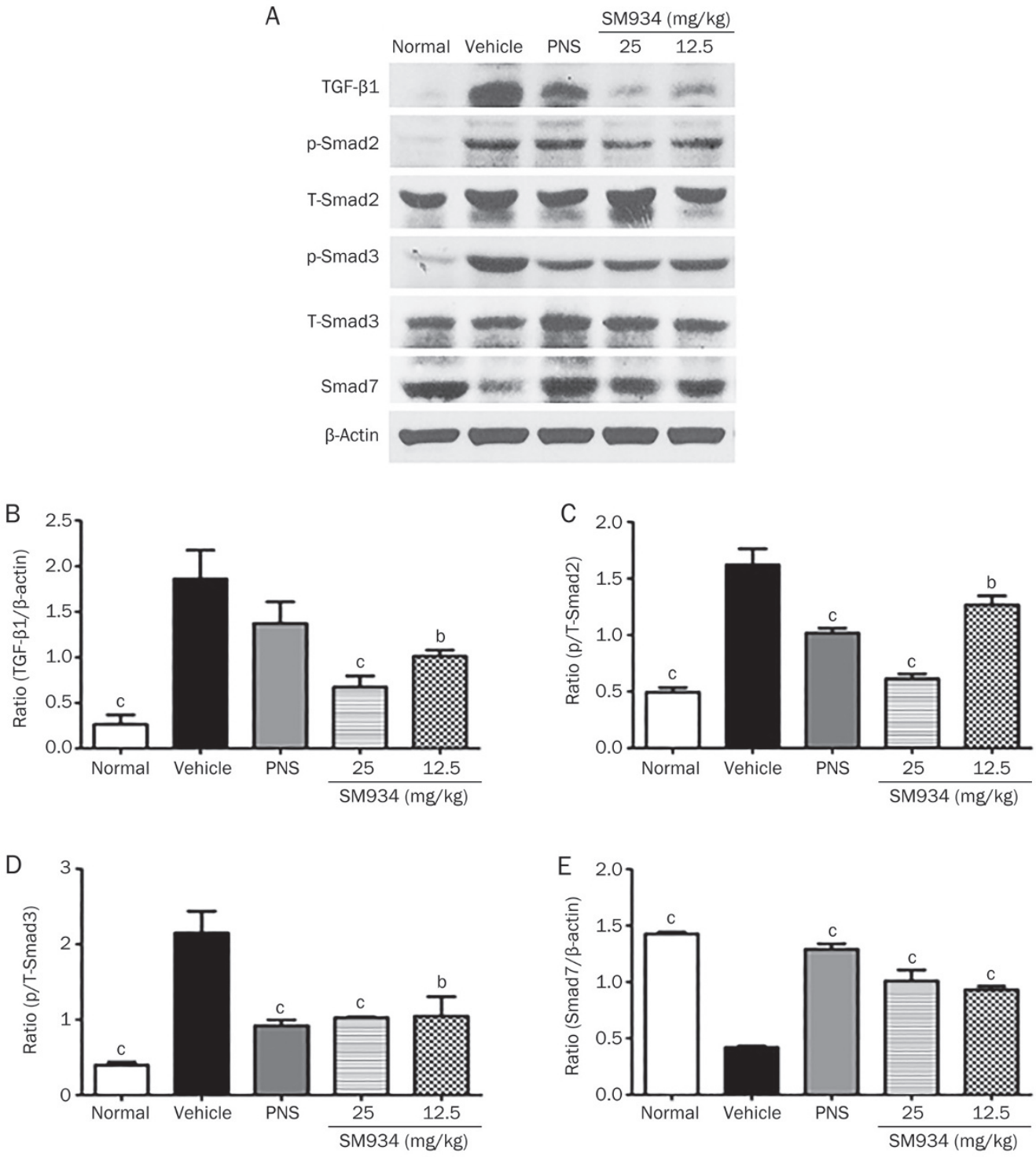

Figure 6. SM934 reduced the expression of TGF- $\beta 1$ in the PHN rats and inhibited the downstream Smad signaling. (A) Western blot result of TGF- $\beta 1$ and several Smad proteins expression in PHN rat kidneys. (B-E) The quantification of the Western blot results of TGF- $\beta 1, p / T$ Smad2, $p / T$ Smad3, Smad7. ${ }^{b} P<0.05,{ }^{c} P<0.01$ vs vehicle treatment group.

number of interstitial myofibroblasts (a-SMA positive) and the expression of collagen (Hyp assay). Therefore, these findings demonstrated that SM934 inhibited the renal fibrosis in the late stage of PHN.

Furthermore, we tried to explore the anti-fibrosis mechanism of SM934. Although numerous different fibrogenic factors have been documented, including various cytokines and hormonal, metabolic factors, increasing evidence shows that TGF- $\beta$ and its downstream Smad signaling play a central role in the pathogenesis of renal fibrosis in both human and experimental models of $\mathrm{MN}^{[15,36,37]}$. Primarily, TGF- $\beta 1$ is an immunoregulatory cytokine, and its moderate expression protects tissues from inflammation. However, once the TGF- $\beta 1$ is overexpressed, the progressive renal injury occurs through stimulating the ECM production while inhibiting its degrada- tion. In the current study, we did observe the upregulation of TGF- $\beta 1$ expression in the kidneys of PHN rats, and SM934 treatment prominently down-regulated TGF- $\beta 1$ expression. The results of our current and previous experiments suggest a tendency that SM934 treatment keeps the TGF- $\beta 1$ expression in the kidney at a level that does not cause fibrosis and shows Foxp3-dependent regulatory function ${ }^{[16]}$.

The detection of the downstream Smad signaling confirmed that SM934 acted on the TGF- $\beta 1 /$ Smad pathway; the treatment down-regulated the phosphorylation of Smad2/3 and up-regulated the Smad7. Notably, Smad7 not only blocks the TGF$\beta 1 /$ Smad pathway by degrading the T $\beta$ R I but also inhibits the NF-KB-driven inflammatory response by inducing $\mathrm{IKB}^{[38,39]}$. Thus, in the PHN rat kidney, the loss of Smad7 results in renal fibrosis as well as enhanced renal inflammation, and it is well 
A

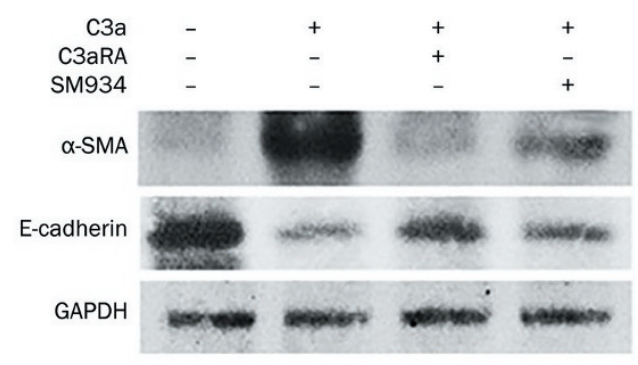

C
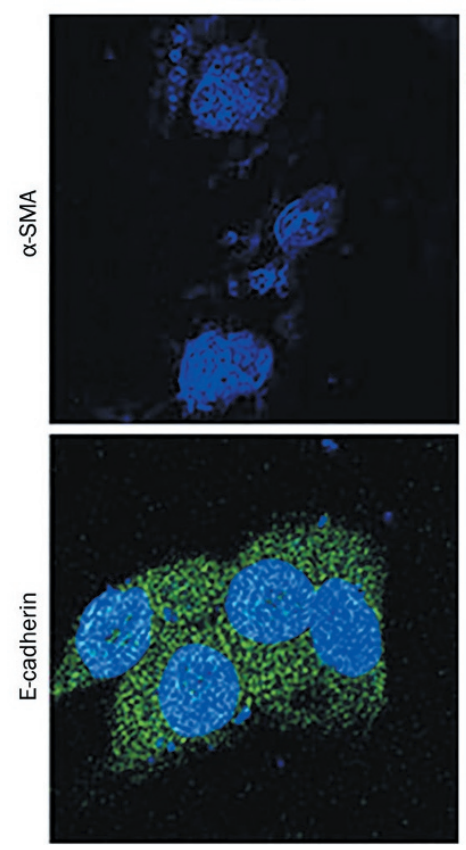

Control
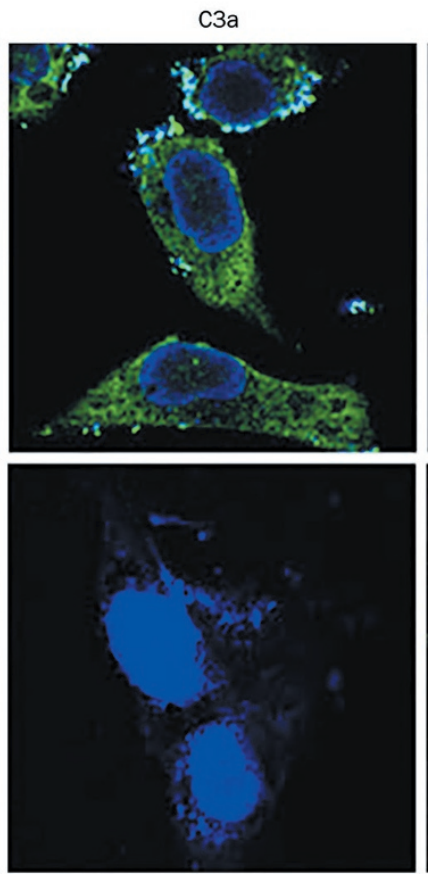

B

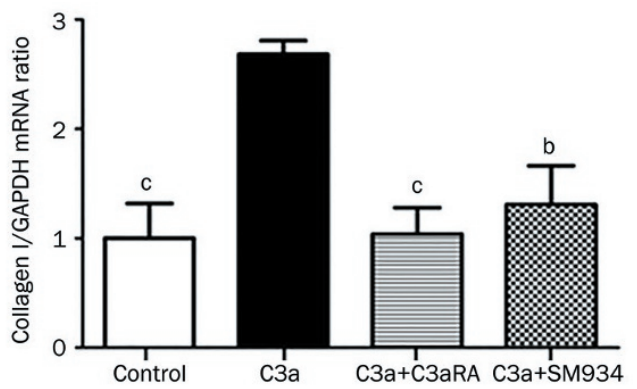

$\mathrm{C} 3 a+\mathrm{C} 3 \mathrm{aRA}$
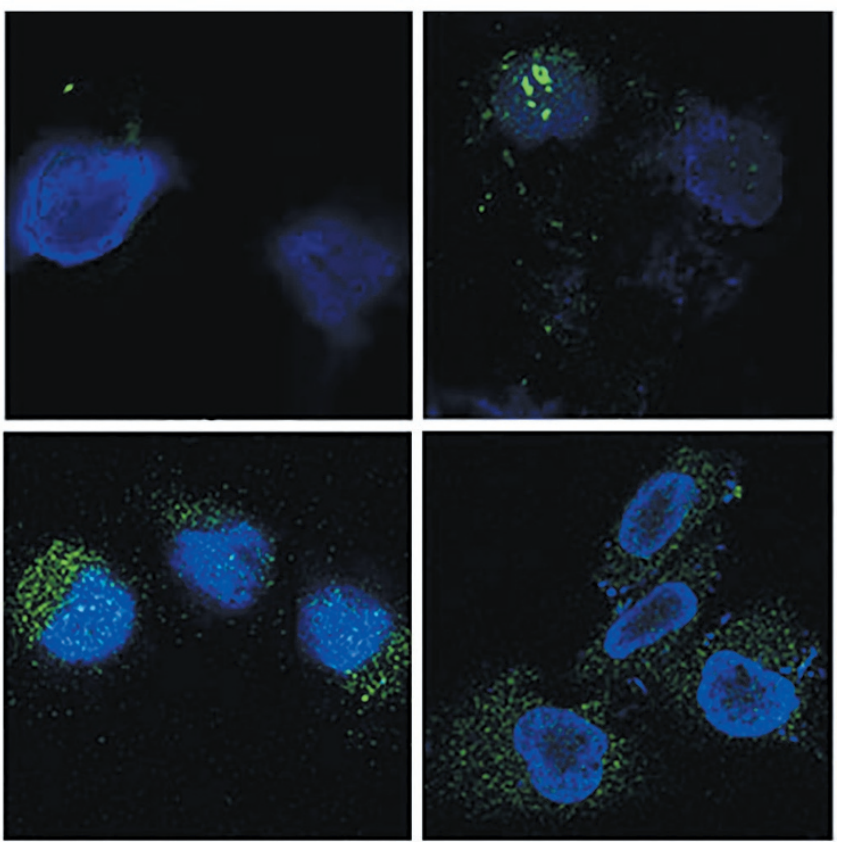

Figure 7. SM934 pretreatment blocked the C3a induced EMT in HK-2 cells. (A) Western blot of $\alpha$-SMA and E-cadherin in HK-2 whole-cell lysates. (B) The real-time PCR result of collagen I mRNA level in C3a induced HK-2 cells. (C) Immunofluorescence staining of $\alpha$-SMA and E-cadherin. ${ }^{b} P<0.05,{ }^{~} P<0.01$ vs C3a treated group.

documented that activation of NF-kB/p65 is associated with the renal inflammation in membranous nephropathy ${ }^{[40,41]}$. The upregulation of Smad7 production after SM934 treatment means SM934 can decrease the renal fibrosis and suppress the renal inflammation through Smad7-dependent pathway.

Macrophages are the main resource of TGF- $\beta 1$ in renal fibrosis, which is well documented ${ }^{[42,43]}$. In the current study, the expression of ED-1, the marker of rat macrophages, was significantly reduced after SM934 treatment in the PHN rat kidney. According to the effect of SM934 on inflammatory cell infiltration and renal fibrosis, we conclude that SM934 is able to restrict the TGF- $\beta 1$ expression by reducing the macrophage infiltration.

Myofibroblasts derived from the tubular epithelial-mesenchymal transition is the most important profibrosis cell type in tubulointerstitial fibrosis. The complement protein C3a can efficiently induce the TEMT and promote the fibrogenesis process in animal and cellular experiments. Herein, we confirmed that the complement system was activated in the PHN rat, therefore we further examined the SM934 effect on C3a induced TEMT in HK-2 cell line. The results demonstrated that SM934 markedly blocked the phenotypic transformation of HK-2 cell. These in vitro results indicated that, in addition to the TGF- $\beta 1 /$ Smad signaling pathway, C3a-induced TEMT might be another important target of SM934 in attenuating the renal fibrogenesis.

In summary, we have demonstrated that treatment with the artemisinin analogue SM934 exerted promising therapeutic effects on rat membranous nephropathy model and possessed great anti-renal fibrosis potential. These effects of SM934 are clearly of potential clinical importance and suggest that SM934 may represent a viable treatment option for the treatment of proteinuric renal diseases in humans. Additional studies would be necessary to further elucidate the mechanism of SM934 on kidney disease.

\section{Acknowledgements}

This work was supported by the grants of National Natural 
Science Foundation of China (NSFC, № 81273524, 81322049, and 81273525), National Science \& Technology Major Project "New Drug Creation and Manufacturing Program", China (No 2014ZX09101002) and National Key Basic Research Programme (973 Programme, № 2014CB541906).

\section{Author contribution}

Jian-ping ZUO, Wei TANG, and Tian-tian LI conceived and designed the experiments.Tian-tian LI, Xiao-hui ZHANG, Jing-feng JING, Xin LI, Xiao-qian YANG, and Feng-hua ZHU performed the experiments: Jian-ping ZUO, Tian-tian LI and Wei TANG analyzed the data: Jian-ping ZUO, Tian-tian LI, and Wei TANG contributed reagents/ materials/ analysis tools: Jian-ping ZUO, Tian-tian LI, and Wei TANG wrote the paper.

\section{References}

1 Pan X, Xu J, Ren H, Zhang W, Xu Y, Shen P, et al. Changing spectrum of biopsy-proven primary glomerular diseases over the past 15 years: a single-center study in China. Contrib Nephrol 2013; 181: 22-30.

2 Glassock RJ. The pathogenesis of idiopathic membranous nephropathy: a 50-year odyssey. Am J Kidney Dis 2010; 56: 157-67.

3 Debiec H, Guigonis V, Mougenot B, Decobert F, Haymann JP, Bensman $A$, et al. Antenatal membranous glomerulonephritis due to antineutral endopeptidase antibodies. N Engl J Med 2002; 346: 205360.

4 Beck LH, Bonegio RGB, Lambeau G, Beck DM, Powell DW, Cummins TD, et al. M-Type phospholipase A2 receptor as target antigen in idiopathic membranous nephropathy. N Engl J Med 2009; 361: 1121.

5 Barbour S, Reich H, Cattran D. Short-term complications of membranous nephropathy. Contrib Nephrol 2013; 181: 143-51.

6 Liu Y. Renal fibrosis: new insights into the pathogenesis and therapeutics. Kidney Int 2006; 69: 213-7.

7 Fervenza FC, Sethi S, Specks U. Idiopathic membranous nephropathy: diagnosis and treatment. Clin J Am Soc Nephrol 2008; 3: 905-19.

8 Liu Y. Cellular and molecular mechanisms of renal fibrosis. Nat Rev Nephrol 2011; 7: 684-96.

9 Liu Y. Epithelial to mesenchymal transition in renal fibrogenesis: pathologic significance, molecular mechanism, and therapeutic intervention. J Am Society Nephrol 2004; 15: 1-12.

10 Tang Z, Lu B, Hatch E, Sacks SH, Sheerin NS. C3a mediates epithelialto-mesenchymal transition in proteinuric nephropathy. J Am Society Nephrol 2009; 20: 593-603.

11 Loverre A, Tataranni T, Castellano G, Divella C, Battaglia M, Ditonno $\mathrm{P}$, et al. IL-17 expression by tubular epithelial cells in renal transplant recipients with acute antibody-mediated rejection. Am J Transplant 2011; 11: 1248-59.

12 Jefferson JA, Pippin JW, Shankland SJ. Experimental models of membranous nephropathy. Drug Discov Today Dis Models 2010; 7: 27-33.

13 Kerjaschki D, Farquhar MG. The pathogenic antigen of Heymann nephritis is a membrane glycoprotein of the renal proximal tubule brush border. Proc Natl Acad Sci U S A 1982; 79: 5557-61.

14 Kerjaschki D, Farquhar MG. Immunocytochemical localization of the Heymann nephritis antigen (GP330) in glomerular epithelial cells of normal Lewis rats. J Exp Med 1983; 157: 667-86.

15 Shankland SJ, Pippin J, Pichler RH, Gordon KL, Friedman S, Gold LI, et al. Differential expression of transforming growth factor-beta isoforms and receptors in experimental membranous nephropathy. Kidney Int 1996; 50: 116-24.

16 Li X, Li TT, Zhang XH, Hou LF, Yang XQ, Zhu FH, et al. Artemisinin analogue SM934 ameliorates murine experimental autoimmune encephalomyelitis through enhancing the expansion and functions of regulatory T cell. PLoS One 2013; 8: e74108.

17 Hou LF, He SJ, Li X, Wan CP, Yang Y, Zhang XH, et al. SM934 treated lupus-prone NZB x NZW F1 mice by enhancing macrophage interleukin-10 production and suppressing pathogenic $\mathrm{T}$ cell development. PLoS One 2012; 7: e32424.

18 Hou LF, He SJ, Li X, Yang Y, He PL, Zhou Y, et al. Oral administration of artemisinin analog SM934 ameliorates lupus syndromes in MRL/ Ipr mice by inhibiting Th1 and Th17 cell responses. Arthritis Rheum 2011; 63: 2445-55.

19 Edgington TS, Glassock RJ, Watson JI, Dixon FJ. Characterization and isolation of specific renal tubular epithelial antigens. J Immunol 1967; 99: 1199-210.

20 He SJ, Lin ZM, Wu YW, Bai BX, Yang XQ, He PL, et al. Therapeutic effects of DZ2002, a reversible SAHH inhibitor, on lupus-prone NZBXNZW F1 mice via interference with TLR-mediated APC response. Acta Pharmacol Sin 2014; 35: 219-29.

21 Shankland SJ, Ly H, Thai K, Scholey JW. Increased glomerular capillary pressure alters glomerular cytokine expression. Circ Res 1994; 75: 844-53.

22 Suddek GM, El-Kenawi AE, Abdel-Aziz A, El-Kashef HA. Celecoxib, a selective cyclooxygenase- 2 inhibitor, attenuates renal injury in a rat model of cisplatin-induced nephrotoxicity. Chemotherapy 2011; 57: 321-6.

23 Saad SY, Al-Rikabi AC. Protection effects of taurine supplementation against cisplatin-induced nephrotoxicity in rats. Chemotherapy 2002; 48: 42-8.

24 Raychowdhury R, Zheng G, Brown D, McCluskey RT. Induction of Heymann nephritis with a gp330/megalin fusion protein. Am J Pathol 1996; 148: 1613-23.

25 Makker SP, Tramontano A. Differential capacity of anti-RAP and anti-megalin antibodies to produce progressive passive Heymann nephritis-implications for the pathogenesis of idiopathic human membranous glomerulonephritis. J Pathol 2006; 210: 282-7.

26 Jefferson JA, Nelson PJ, Najafian B, Shankland SJ. Podocyte disorders: Core Curriculum 2011. Am J Kidney Dis 2011; 58: 666-77.

27 Haraldsson B, Jeansson M. Glomerular filtration barrier. Curr Opin Nephrol Hypertens 2009; 18: 331-5.

28 Herrmann A, Tozzo E, Funk J. Semi-automated quantitative image analysis of podocyte desmin immunoreactivity as a sensitive marker for acute glomerular damage in the rat puromycin aminonucleoside nephrosis (PAN) model. Exp Toxicol Pathol 2012; 64: 45-9.

29 Konkimalla VB, Blunder M, Korn B, Soomro SA, Jansen H, Chang W, et al. Effect of artemisinins and other endoperoxides on nitric oxiderelated signaling pathway in RAW 264.7 mouse macrophage cells. Nitric Oxide 2008; 19: 184-91.

30 Wang Z, Qiu J, Guo TB, Liu A, Wang Y, Li Y, et al. Anti-inflammatory properties and regulatory mechanism of a novel derivative of artemisinin in experimental autoimmune encephalomyelitis. J Immunol 2007; 179: 5958-65.

31 Salant DJ, Darby C, Couser WG. Experimental membranous glomerulonephritis in rats. Quantitative studies of glomerular immune deposit formation in isolated glomeruli and whole animals. J Clin Invest 1980; 66: 71-81.

32 Yuan H, Takeuchi E, Taylor GA, McLaughlin M, Brown D, Salant DJ. Nephrin dissociates from actin, and its expression is reduced in early experimental membranous nephropathy. J Am Soc Nephrol 2002; 13: 
946-56.

33 Tang S, Leung JC, Abe K, Chan KW, Chan LY, Chan TM, et al. Albumin stimulates interleukin-8 expression in proximal tubular epithelial cells in vitro and in vivo. J Clin Invest 2003; 111: 515-27.

34 Morigi M, Macconi D, Zoja C, Donadelli R, Buelli S, Zanchi C, et al. Protein overload-induced NF-kappaB activation in proximal tubular cells requires $\mathrm{H}_{2} \mathrm{O}_{2}$ through a PKC-dependent pathway. J Am Soc Nephrol 2002; 13: 1179-89.

35 Bonegio RG, Fuhro R, Wang Z, Valeri CR, Andry C, Salant DJ, et al. Rapamycin ameliorates proteinuria-associated tubulointerstitial inflammation and fibrosis in experimental membranous nephropathy. J Am Soc Nephrol 2005; 16: 2063-72.

36 Bottinger EP. TGF-beta in renal injury and disease. Semin Nephrol 2007; 27: 309-20.

37 Yoshioka K, Takemura T, Murakami K, Okada M, Hino S, Miyamoto H, et al. Transforming growth factor-beta protein and mRNA in glomeruli in normal and diseased human kidneys. Lab Invest 1993; 68: 15463.

38 Wang W, Huang XR, Li AG, Liu F, Li JH, Truong LD, et al. Signaling mechanism of TGF-beta1 in prevention of renal inflammation: role of Smad7. J Am Soc Nephrol 2005; 16: 1371-83.

39 Huang XR, Chung AC, Zhou L, Wang XJ, Lan HY. Latent TGF-beta1 protects against crescentic glomerulonephritis. J Am Soc Nephrol 2008; 19: 233-42.

40 Donadelli R, Abbate M, Zanchi C, Corna D, Tomasoni S, Benigni A, et al. Protein traffic activates NF-KB gene signaling and promotes MCP1-dependent interstitial inflammation. Am J Kidney Dis 2000; 36: 1226-41.

41 Nangaku M. Mechanisms of tubulointerstitial injury in the kidney: final common pathways to end-stage renal failure. Intern Med 2004; 43: 9-17.

42 Wang Y, Wang Y, Cao Q, Zheng G, Lee VW, Zheng D, et al. By homing to the kidney, activated macrophages potently exacerbate renal injury. Am J Pathol 2008; 172: 1491-9.

43 Ko GJ, Boo CS, Jo SK, Cho WY, Kim HK. Macrophages contribute to the development of renal fibrosis following ischaemia/reperfusioninduced acute kidney injury. Nephrol Dial Transplant 2008; 23: 842-52. 